\title{
Prevalence of Hypertension in a Population of Healthy Individuals
}

\author{
Ashraf M. Elkhalifa ${ }^{a} \quad$ Abdulhalim Jamal Kinsara $^{a}$ Doha A. Almadani ${ }^{b}$ \\ ${ }^{a}$ Cardiology Section, Department of Medicine, and ${ }^{\mathrm{b}}$ King Abdullah International Medical Research Center, \\ King Abdulaziz Medical City, Jeddah, Kingdom of Saudi Arabia
}

\section{Key Words}

Hypertension • Prevalence $\cdot$ Saudi Arabia $\cdot$ Jeddah

\begin{abstract}
Objectives: To assess the prevalence of hypertension (HTN) in a random sample of individuals in Jeddah, Kingdom of Saudi Arabia. Subjects and Methods: A total of 243 participants were randomly selected at a megamall in Jeddah, on May 2008. Questionnaires were distributed to all the participants by one of the researchers, who explained the purpose of the study and the content of the questionnaire. The questionnaire was designed to gather information regarding the prevalence of HTN in the general population in addition to identifying other risk factors associated with HTN. Notably, accurate blood pressure measurements were performed on all the participants. Results: Of the 243 participants, 55 (22.6\%) were hypertensive. Of these, 28 (50.9\%) were males and $27(49.1 \%)$ females. The probability of having HTN was significantly higher with increasing age with 7 (38.9\%) of the participants $>50$ years of age. Similarly, HTN increased proportionately with the participant's body mass index. With regard to other risk factors, $13(50 \%)$ of the diabetics, 10 (27.0\%) of the dyslipidemic participants and 9 (18.4\%) of the
\end{abstract}

cigarette-smoking participants had HTN. Conclusions: The occurrence of HTN was high and was strongly associated with diabetes, the aging process and obesity.

Copyright $\odot 2011$ S. Karger AG, Basel

\section{Introduction}

Hypertension (HTN) is a chronic condition and a major public health problem [1]. HTN can adversely affect the health status of individuals, families and communities, and it directly affects the quality of health and possibly the quality of life in the general population. Thus the prevalence of HTN is an important determinant of the need for new health services [2].

HTN is one of the most common conditions that require lifelong treatment, and there is ample evidence that such treatment substantially reduces the risk of cerebrovascular accidents and coronary artery disease [3-6]. Each year, in the UK approximately 100,000 people suffer their first stroke and 64,000 die as a result [7]. HTN is one of the most common causes of heart failure among the elderly. Cardiovascular diseases are responsible for about $33 \%$ of all hospital admissions of the elderly [8]. There-

\section{KARGER}

Fax +4161306 1234

E-Mail karger@karger.ch

www.karger.com
(C) 2011 S. Karger AG, Basel

1011-7571/11/0202-0152\$38.00/0

Accessible online at:

www.karger.com/mpp
Dr. Abdulhalim J. Kinsara, FRCP, FACC

Head of Cardiology Section, King Abdulaziz Medical City PO Box 9515, Jeddah 21423 (Kingdom of Saudi Arabia)

Tel. +9662 6240000 ext. 21685, Fax +966 26240000 ext. 21688

E-Mail akinsara@yahoo.com 
fore, it is important to know the degree to which HTN affects the entire community. The purpose of this study was to ascertain the prevalence of HTN in the general population, using a random sample of individuals visiting a megamall in Jeddah, Kingdom of Saudi Arabia. The prevalence of HTN had been not addressed in the Jeddah area as an isolated region, so our data would help the strategic planning of the health care system in this area.

\section{Subjects and Methods}

This study was conducted by distributing self-administered questionnaires to a sample of 243 individuals visiting a megamall in Jeddah in May 2008 who voluntarily participated in the HTN day community awareness program. The questionnaire was designed to gather information on the prevalence of HTN in the general population in addition to determining other risk factors that are associated with HTN. The questionnaire was distributed to the participants by one of the researchers (A.M.E.), who explained the purpose of the study and the content of the questionnaire, which did not require the participant to be identified by name. Thus, confidentiality was strictly maintained in all the completed questionnaires. The subjects were asked if they were aware of having HTN and/or were taking antihypertensive medications. The study was approved by the hospital research committee. An accurate blood pressure measurement was the first part of the evaluation, as it was for the treatment of a patient with HTN. HTN was defined as blood pressure of $>140 / 90 \mathrm{~mm}$ $\mathrm{Hg}$. In our study, all the participants were asked to sit comfortably for 5 min prior to the examination. During the examination, the participant's back was fully supported while the brachial artery was held at the level of the participant's heart. All the data management and analyses were performed using the SPSS statistical program (version 11.5). The analysis was age group based ( $\leq 30,31-40,41-50$ and $>50$ years), while the body mass index (BMI) groups were formed according to scores of $<25,25-$ 29 and $\geq 30$ calculated by the formula: $\mathrm{BMI}=$ mass $(\mathrm{kg}) /$ height $^{2}$ $\left(\mathrm{m}^{2}\right)$.

\section{Results}

A total of 243 participants completed the questionnaires. Of these 243 participants, $112(46.1 \%)$ were males and 131 (53.9\%) females. Of the 243 participants, 55 (22.6\%) were hypertensive, of whom 28 (50.9\%) were males and 27 (49.1\%) females. Hence, the prevalence in males and females was approximately the same. The median systolic blood pressure was $148 \mathrm{~mm} \mathrm{Hg}$ (SE: $1.7 \mathrm{~mm}$ Hg; 95\% CI: 148.4-155.3 mm Hg), the median diastolic blood pressure was $95.5 \mathrm{~mm} \mathrm{Hg}$ (SE: $1.09 \mathrm{~mm} \mathrm{Hg}$; 95\% CI: 93.8-98.3 mm Hg).

Hypertension in the Saudi Community

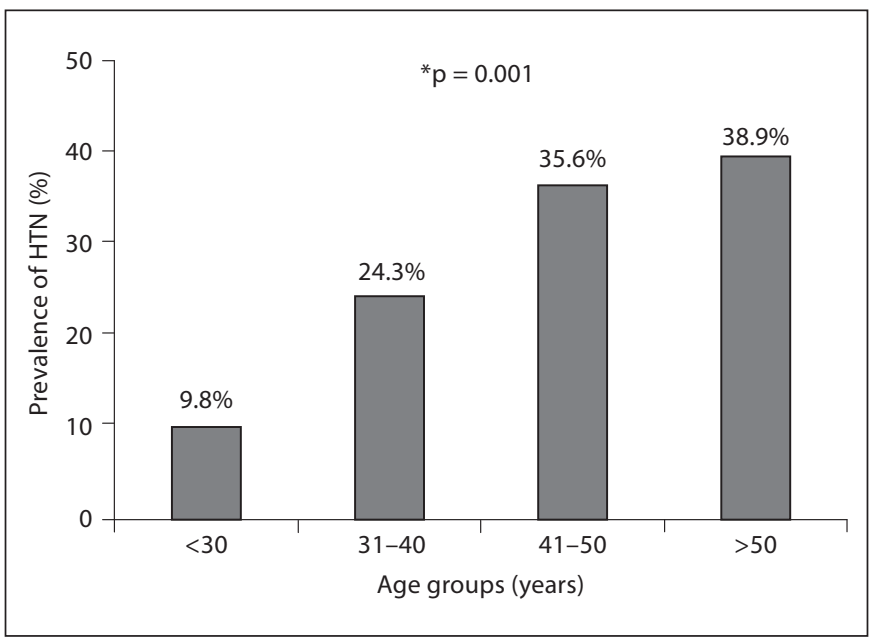

Fig. 1. Prevalence of HTN in different age groups.

Table 1. HTN and body weight

\begin{tabular}{lccc}
\hline & Normal & Hypertensive & Total \\
\hline Normal weight $($ BMI $<25)$ & 58 & $7(10.8)$ & $65(26.7)$ \\
Overweight $($ BMI 25 to $<30)$ & 67 & $12(15.2)$ & $79(32.5)$ \\
Obesity (BMI $\geq 30)$ & 63 & $36(36.4)$ & $99(40.7)$ \\
\hline Total & 188 & $55(22.6)$ & $243(100)$ \\
\hline
\end{tabular}

Figures in parentheses are percentages. $\mathrm{p}=0.000$.

The incidence of HTN across the different age groups revealed strong evidence of an increasing probability of HTN with increasing age (fig. 1). The correlation coefficient between age and mean arterial pressure (MAP) was equal to 0.362 , with a positive direction. A $\chi^{2}$ test revealed a significant difference between the 4 different groups $\left(\chi^{2}=17.17 ; p=0.001\right)$, as indicated by the observation that only $9(9.8 \%)$ of the hypertensive participants were less than 30 years of age, while 7 (38.9\%) of the hypertensive patients were above the age of 50 years (fig. 1). The prevalence of HTN increased proportionally with BMI. The correlation coefficient between BMI and MAP was equal to 0.33 , with a positive direction; the $\chi^{2}$ test revealed a significant difference between the 3 different groups of normal, obese and overweight participants $\left(\chi^{2}=18.4\right.$; $\mathrm{p}=0.000$ ). The correlation coefficient between BMI and MAP was equal to 0.33 , as indicated by an HTN prevalence of $15.2 \%$ in overweight patients and of $36.4 \%$ in obese patients (table 1). 


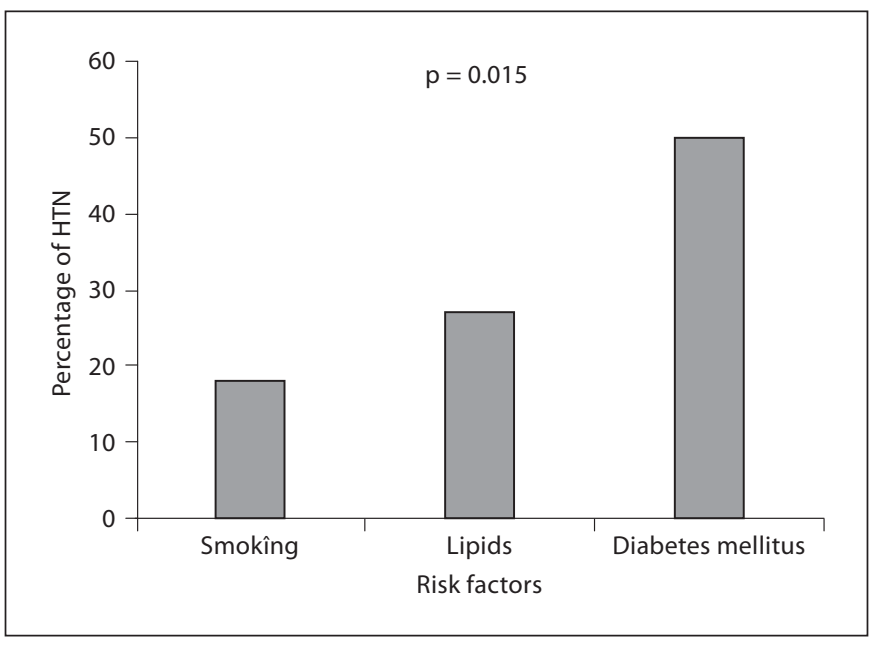

Fig. 2. Percentage of HTN among different risk factors.

The different risk factors for coronary artery disease were interrelated, with some participants having more than 1 risk factor. While 9 (18.4\%) of those who smoked among the screened population were hypertensive, half of the diabetic participants (26 individuals) and a third of the 37 dyslipidemic participants were hypertensive $\left(\chi^{2}=\right.$ 8.4; $\mathrm{p}=0.015$ ) (fig. 2).

\section{Discussion}

The $22.6 \%$ prevalence of HTN in our study was higher than those of previous studies in various regions of Saudi Arabia [9-14]: 10\% in Almadin Al Munawarah [9], 15.2\% in the Northern Province [10], 2.4\% in Asir [11], 11.1\% in the South West and 8.7-9.1\% in other areas [13]. Of note is that the prevalence of HTN among males and females in our study was approximately equal, as in the study by El-Hazmi et al. [15]. In all these studies, the investigators used a blood pressure cutoff of 160/95 $\mathrm{mm} \mathrm{Hg}$, the old WHO criterion for defining HTN.

However, the $22.6 \%$ prevalence of HTN in our study is comparable to the $30 \%$ in Al-Qassim [16], where a cutoff of $140 / 90 \mathrm{~mm} \mathrm{Hg}$ was used to define HTN. In this study, the researchers found that parameters including age (above 40 years old), illiteracy and the conditions of being overweight and obese were independently associated with HTN [16]. Similarly, a larger-scale screening program performed across the country reported a $28.6 \%$ prevalence of HTN among males and $23.9 \%$ prevalence among females [17]. In this case, a linear relationship was also observed between increasing weight and the prevalence of HTN. In a primary health care clinic in Riyadh, the incidence of HTN was highest among diabetic patients (40\%), followed by dyslipidemic patients (19\%) and smokers (8\%) [18]. Similar results were observed in our study. The strong association of HTN with these risk factors suggests that HTN is often part of the metabolic syndrome in Jeddah.

With the new guidelines, more cases are being discovered. It is noteworthy that the incidence of HTN in urban communities was usually different from that observed in rural communities.

The limitation of the study was the small sample size, and it may not be fully representative of the general population as selection biases might have occurred, such as the exclusion of people who were not mobile and of people who were either very rich or very poor. However, because of the hot weather, a large popular indoor shopping center would be just about as representative of the ambulatory community as one can get. The sample size was too small to allow for any subgroup analysis, but large enough to obtain an approximate estimate of the prevalence, and the results revealed the level of HTN in the Jeddah population and suggest that a larger and more extensive study is warranted.

It is worth pointing out that the one-off measurement of blood pressure may have overestimated the prevalence of HTN in our study.

\section{Conclusion}

This study showed a high prevalence of HTN requiring medical attention among healthy individuals in Saudi Arabia. In addition, diabetes, aging and BMI were the most important determinant factors for HTN.

\section{Acknowledgment}

We would like to acknowledge our gratitude to Dr. Ayman H. Elshiekh, Dr. Amr I. Abdelrasoul and Dr. Adel M. Hasanin for their help in collecting the data and for helpful comments regarding the manuscript. In addition, we would like to thank all of the cardiology technicians for their help in conducting the survey. 


\section{References}

$>1$ Aminoff U, Kjellgren K: The nurse: a resource in hypertension care. J Adv Nurs 2001;35:582-589.

$\checkmark 2$ Hashim T, Anokute C, Al-Shammary F, Khoja T, Saeed A, Khan S: Hypertension awareness: treatment and control among adult hypertensives. Saudi Med J 1998;19: 707-712.

$\checkmark 3$ MacMahon S, Stamler J, Peto R, Cutler J, Collins R, Sørlie P, Neaton J, Abbott R, Godwin J, Dyer A: Blood pressure, stroke, and coronary heart disease. Part 1. Prolonged differences in blood pressure: prospective observational studies corrected for the regression dilution bias. Lancet 1990;335:765774.

$>4$ World Health Organization: Arterial hypertension. Report of a WHO expert committee. World Health Organ Tech Rep Ser 1978;628: 7-56.

$\checkmark 5$ Yamani M, Massie B: Hypertension, myocardial ischemia and sudden death. Curr Opin Cardiol 1994;9:542-550.
6 Petrovitch H, Curb J, Bloom-Marcus E: Isolated systolic hypertension and risk of stroke in Japanese-American men. Stroke 1995;26: 25-29.

7 Dennis M, Warlow C: Strategy for stroke. BMJ 1991;303:636-638.

-8 Al-Balla S, Bamgboye E, Sekait M, Balla M: Causes of morbidity in the elderly population of Saudi Arabia. J Trop Med Hyg 1993 96:157-162.

$\checkmark 9$ Ahmed A, Mahmoud M: The prevalence of hypertension in Saudi Arabia. Saudi Med J 1992;13:548-551.

10 Nazim Uddin K: Prevalence of hypertension in Saudi Arabia. Pract East Mediterr Ed 1994;11:805-806.

11 Mahfouz A, Al-Erian R: Hypertension in Asir region, south western Saudi Arabia: an epidemiologic study. Southeast Asian J Trop Med Public Health 1993;24:284-286.

12 Abolfotouh M, Abu-Zeid H, AbdelAziz M, Alakija W, Mahfouz A, Bassuni W: Prevalence of hypertension in South-Western Saudi Arabia. East Mediterr Health J 1996;2: 211-218.

13 Al-Nozha M, Ali M, Osman A: Arterial hypertension in Saudi Arabia. Ann Saudi Med 1997; 17:170-174.
14 Al-Nozha M, Osman A: The prevalence of hypertension in different geographical regions of Saudi Arabia. Ann Saudi Med 1998; 18:401-407.

15 El-Hazmi M, Warsy A, Al-Swailem A, AlSwailem A: Prevalence of hypertension in adult Saudi population. Saudi Med J 1998;19: 117-122.

16 Kalantan K, Mohamed A, Al Taweel A, Abdul Ghani H: Hypertension among attendants of primary health care centers in AlQassim region, Saudi Arabia. Saudi Med J 2001;22:960-963.

17 Al-Nozha M, Abdullah M, Arafah M, Khalil M, Khan N, Al-Mazrou Y, Al-Maatouq M, Al-Marzouki K, Al-Khadra A, Nouh MS, AlHarthi S, Al-Shahid M, Al-Mobeireek A: Hypertension in Saudi Arabia. Saudi Med J 2007;28:77-84

18 Al-Tuwijri A, Al-Rukban M: Hypertension control and co-morbidities in primary health care centers in Riyadh. Ann Saudi Med 2006;26:266-271. 